\title{
Grid Power Quality Enhancement Using Fuzzy Control-Based Shunt Active Filtering
}

\author{
Abdeldjabbar Kouadria \\ Energetic and Computer Engineering Lab \\ University of Tiaret \\ Tiaret, Algeria \\ abdeldjabbar14@yahoo.fr \\ Tayeb Allaoui \\ Energetic and Computer Engineering Lab \\ University of Tiaret \\ Tiaret, Algeria \\ allaoui_tb@yahoo.fr
}

\author{
Mouloud Denaï \\ School of Engineering and Technology \\ University of Hertfordshire \\ Hatfield, UK \\ m.denai@herts.ac.uk \\ George Pissanidis \\ School of Engineering and Technology \\ University of Hertfordshire \\ Hatfield, UK \\ g.1.pissanidis@herts.ac.uk
}

\begin{abstract}
Active filtering has proved efficient for the mitigation of harmonics in distribution grids. This paper deals with the design of fuzzy control strategies for a three-phase shunt active filter to enhance the power quality via the regulation of the DC bus voltage of the distribution network. The proposed control scheme is based on Interval Type 2 Fuzzy Logic controller. A simulation study is performed under Simulink/Matlab to evaluate the performance and robustness of the proposed control scheme.
\end{abstract}

Keywords—shunt active power filter, power quality, harmonic distorsions, type 2 fuzzy logic.

\section{INTRODUCTION}

Power quality issues have become a major concern in recent years due to the widespread use of nonlinear loads such power electronic converters, variable speed motor drives and consumer electronics. Nonlinear loads introduce harmonics into the power network which cause a number of disturbances such as distortion of the current and voltage waveforms, electromagnetic interference, overheating of power distribution components inducing losses and reducing their lifetime [1], [2]. Active Power Filters (APFs) also called Active Power Line Conditioners (APLCs) are a relatively new technology which offers a more flexible alternative and provides superior filtering performance characteristics and faster transient response as compared to conventional passive filters consisting of customdesigned LC filters which are tuned to provide fixed frequency compensation [3].

AFPs basically consist of a power electronic inverter and a control circuit. The performance of these filters systems depends mainly on the converter topology employed, the adopted reference current generation strategy for harmonic compensation as well as the controller for the regulation of the $\mathrm{DC}$ bus voltage. The regulation of the DC bus voltage consists of maintaining the voltage across the capacitor connected to the inverter at the desired level. The role of the capacitor voltage is to compensate for inverter losses and any transient fluctuations in real power between the AC and DC sides following load changes. Various DC bus voltage control strategies have been proposed in the literature $[4,5]$.

Fuzzy systems have evolved for more than four decades and have proved to be a powerful technique in dealing with uncertainties, parameter variation and especially where the system model is complex or not accurately defined for the designed control action. They have been successfully implemented in many real world applications mainly focusing on quantitative modeling and control [6]. This paper presents a simplified design approach of an Interval Type-2 fuzzy logic controller (IT2FLC) [7,8] for DC bus voltage regulation. The proposed control strategies are evaluated through extensive simulation under various operating conditions of the SAPF such as system's parameters and nonlinear load variations.

The rest of the paper is organized as follows: Section 2 overviews the basic structure and control scheme of the shunt active power filter. Section 3 presents the proposed control strategy for the DC voltage. In Section 4, the overall system performance is evaluated and the simulations results are presented and discussed. Finally, Section 5 presents the conclusions of this work.

\section{SHunt AFP CONFIGURATION AND CONTROL SCHEME}

\section{A. Shunt AFP Configuration}

The APF concept is to use an inverter to produce specific currents or voltages harmonic components to cancel the harmonic components generated by the load. The most commonly used AFP configuration is the Shunt APF (SAPF) 
which injects current harmonics into the point of common coupling (PCC). Fig. 1 shows basic principle of SAPF.

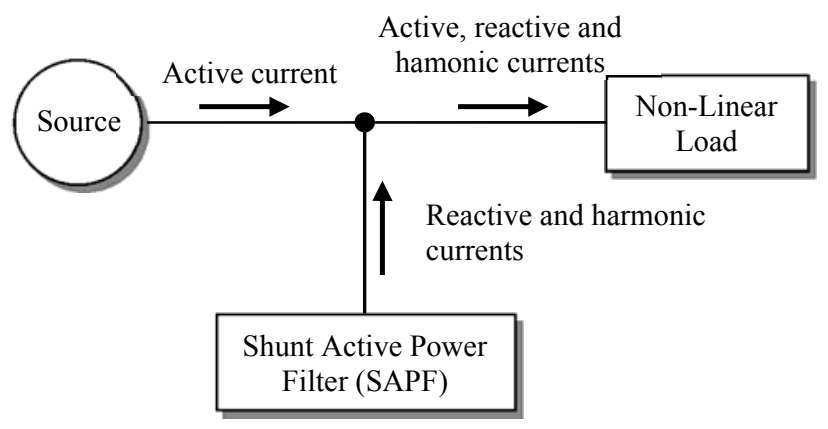

Fig. 1 Basic principle of a SAPF.

\section{B. Control Scheme of the SAPF}

The SAPF control strategy is implemented in three basic stages: The first is the harmonic detection method to identify harmonic level in the system. The second part is to derive the compensating currents and the third one is the control technique of the inverter for injecting these currents into the power system. The overall control system of the SAFP is depicted in Fig. 2.

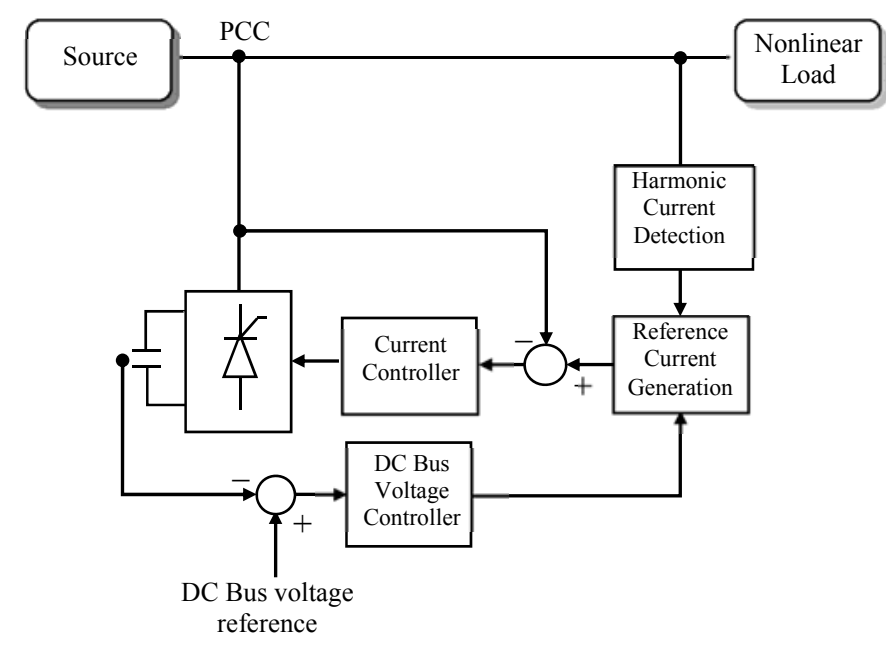

Fig. 2 SAFP control system implementation.

The Synchronous Detection Method (SDM) [9] is used here to calculate the reference current for SAPF due to its simplicity. It is based on the idea that the APF forces the source current to be sinusoidal and in phase with the source voltage despite the load variations.

In this algorithm, the peak values of source currents are assumed to be balanced after compensation.

$$
I_{a m}=I_{b m}=I_{c m}=I_{m}
$$

Peak values of active current in each phase after compensation

$$
I_{a m}=\frac{2 \times p_{a}}{V_{a m}} \quad I_{b m}=\frac{2 \times p_{b}}{V_{b m}} \quad I_{c m}=\frac{2 \times p_{c}}{V_{c m}}
$$

Where $p_{a}, p_{b}$ and $p_{c}$ are real powers from each of the phases and $V_{\mathrm{am}}, \mathrm{V}_{\mathrm{bm}}$ and $\mathrm{V}_{\mathrm{cm}}$ are peak values of phase voltages in the three phases. From equations (1) and (2):

$$
\frac{2 \times p_{a}}{V_{a m}}=\frac{2 \times p_{b}}{V_{b m}}=\frac{2 \times p_{c}}{V_{c m}}
$$

The total average power is:

$$
P_{a v}=p_{a}+p_{b}+p_{c}
$$

Rearranging gives:

$$
p_{a}=\frac{V_{a m}}{V_{t}} p_{a v} ; p_{b}=\frac{V_{b m}}{V_{t}} p_{a v} ; p_{c}=\frac{V_{c m}}{V_{t}} p_{a v}
$$

Where

$$
V_{t}=V_{a m}+V_{b m}+V_{c m}
$$

The balanced current can be determined as:

$$
\begin{aligned}
& i_{s a}=\frac{2 \times V_{a} \times p_{a}}{V_{a m}^{2}} \\
& i_{s b}=\frac{2 \times V_{b} \times p_{b}}{V_{a m}^{2}} \\
& i_{s c}=\frac{2 \times V_{c} \times p_{c}}{V_{c m}^{2}}
\end{aligned}
$$

The compensation current references are thus,

$$
\begin{aligned}
& i_{c a}^{*}=i_{s a}-i_{a} \\
& i_{c b}^{*}=i_{s b}-i_{b} \\
& i_{c c}^{*}=i_{s c}-I_{c}
\end{aligned}
$$

The reference currents are then compared with the actual currents using hysteresis current comparator to generate the control signals for the inverter IGBT switches.

\section{Proposed Control Strategy For The DC Bus VOLTAGE}

The capacitor that powers the active filter acts as voltage source and its voltage must be kept constant to ensure that the performance of the filter is maintained and the voltage fluctuations of the semi-conductors do not exceed the limits prescribed [16]. The Interval Type 2 Fuzzy Logic Controller (IT2FLC) is implemented as shown in Fig. 3. 


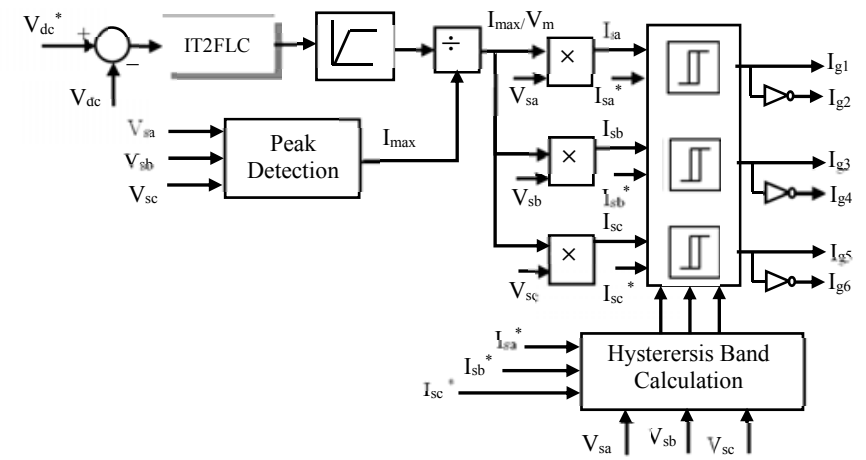

Fig. 3 Implementation of IT2FLC controller for the SAPF.

Type-2 fuzzy logic systems, introduced by Zadeh (1975) as an extension of ordinary Type-1 fuzzy logic systems, are characterized by fuzzy membership functions represented by fuzzy sets in $[0,1]$ unlike a Type-1 fuzzy which have crisp membership functions. T2FLC consists of five components including fuzzifier, rule base, fuzzy inference mechanism, typereducer and defuzzifier as depicted in Fig. 4.

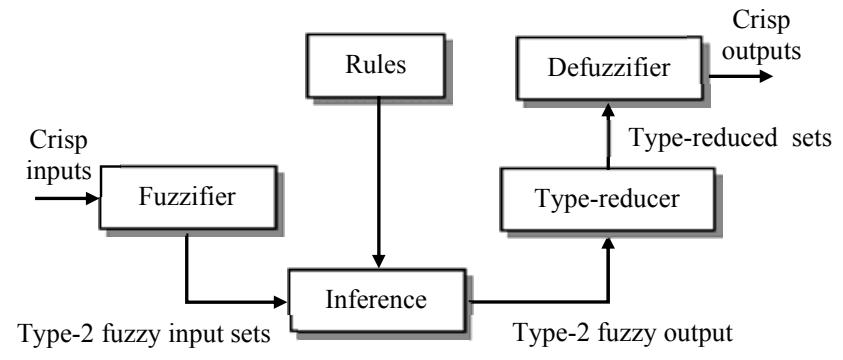

Fig. 4 Interval Type-2 fuzzy system (IT2FLS).

In a IT2FLC at least some of the fuzzy sets used in the antecedent and/or consequent parts and each rule inference output are type- 2 fuzzy sets. Generally speaking, in a T2FLC, the crisp inputs are first fuzzified, usually into Type- 2 fuzzy sets. The fuzzified Type- 2 fuzzy sets then activate the inference engine and rule base to yield output Type-2 fuzzy sets by performing the union and intersection operations of Type-2 fuzzy set and compositions of Type-2 relations. Then a typereduction process is applied to these output sets in order to generate Type-1 fuzzy sets (called type-reduced sets) by combining these output sets and performing a centroid calculation. Finally, the type-reduced Type-1 set is defuzzified to produce crisp output $[7,10]$.

A generalized rule for Type-2 fuzzy system is:

$$
\begin{gathered}
\text { IF } x_{1} \text { is } \bar{A}_{k 1} \text { and } x_{2} \text { is } \bar{A}_{k 2} \text { and ... and } x_{n} \text { is } \bar{A}_{k n} \\
\text { THEN } u_{k}=\sum_{i=1}^{n} p_{i k} x_{i}+b_{k}
\end{gathered}
$$

Where $x_{k}$ 's and $u_{k}$ 's are the input and output linguistic variables respectively; $\bar{A}_{k i}$ 's are Type-2 fuzzy sets for the $\mathrm{k}^{\text {th }}$ rule and $\mathrm{i}^{\text {th }}$ input; $p_{k i}$ and $b_{k}$ are consequent parameters of the rules which are Type- 1 fuzzy sets.

The fuzzy controller inputs (DC bus voltage error $(e)$ and change of error (de)) are implemented using Gaussian membership functions as shown in Fig. 5. The fuzzy labels are negative $(\mathrm{N})$, environ zero $(\mathrm{EZ})$, positive $(\mathrm{P})$.
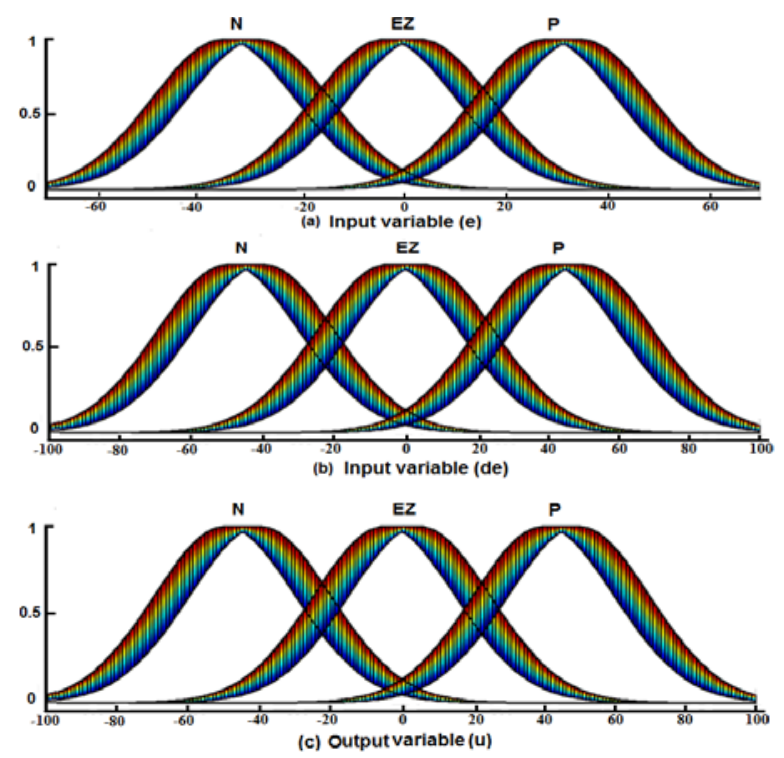

Fig.5 Membership functions for (a) error and (b) change of error and (c) control (u).

The control rules are given in Table 1.

TABLE I. IT2FLC FUZZY CONTROL RULES

\begin{tabular}{|c|c|c|c|}
\hline $\mathbf{e}$ & $\mathbf{N}$ & $\mathbf{E Z}$ & $\mathbf{P}$ \\
\hline $\mathbf{N}$ & $\mathrm{N}$ & $\mathrm{N}$ & EZ \\
\hline $\mathbf{E Z}$ & $\mathrm{N}$ & $\mathrm{EZ}$ & $\mathrm{P}$ \\
\hline $\mathbf{P}$ & $\mathrm{EZ}$ & $\mathrm{P}$ & $\mathrm{P}$ \\
\hline
\end{tabular}

\section{SimULATION RESUlTS}

The SAPF model and controller have been implemented using Simulink and SimPowerSystems toolboxes. The model parameters used for these simulations are listed in Table 2.

In this simulation study, the performance of IT2FLC designed for the DC bus voltage are first analysed in terms of current waveforms and related Total Harmonic Distortion (THD). The robustness of these controllers is then compared with respect to changes in the filter inductance $L_{f}$. 
TABLE II. SYSTEM PARAMETERS

\begin{tabular}{|l|c|c|}
\hline \multicolumn{2}{|c|}{ System Parameter } & Value \\
\hline Three Phase Source Voltage & $V_{s}$ & $220 \mathrm{~V}$ \\
\hline Frequency & $f$ & $50 \mathrm{~Hz}$ \\
\hline Nonlinear Load & $R_{s}, L_{s}$ & $3.12 \Omega, 2500 \mu \mathrm{H}$ \\
\hline Filter inductance & $L_{f}$ & $3 \mathrm{mH}$ \\
\hline DC Capacitance & $C_{d c}$ & $2200 \mu \mathrm{F}$ \\
\hline DC Reference Voltage & $V_{d c}$ & $700 \mathrm{~V}$ \\
\hline
\end{tabular}

\section{A. Simulation results using without filter}

Initially, the system is simulated without the SAPF. Fig. 6(a) and Fig. 6(b) show the load voltage and current respectively which demonstrates a considerable distortion in the current waveform. The THD in Fig. 6(c) has been estimated to $23.74 \%$.

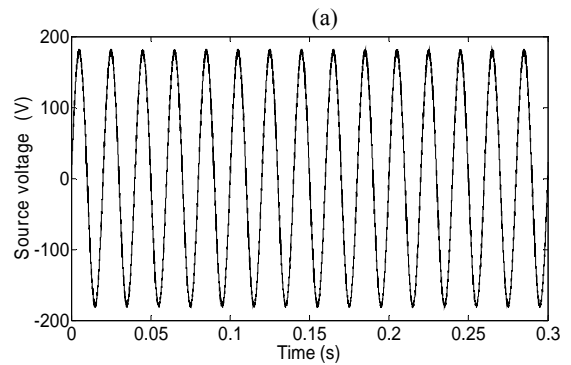

(b)

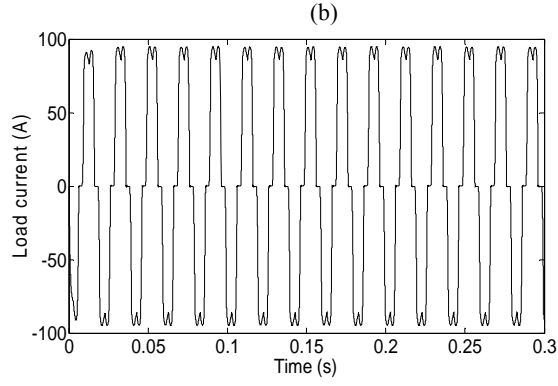

(c)

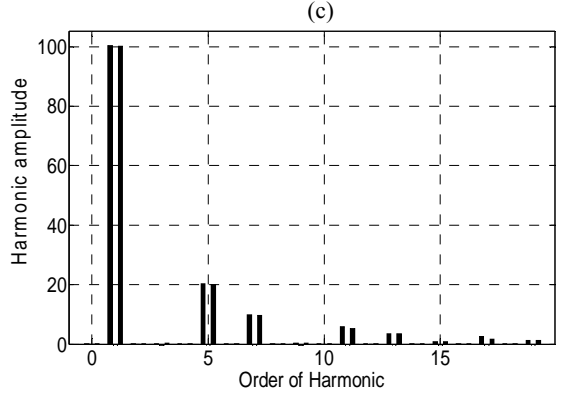

Fig. 6 Source voltage and current without SAPF.

\section{B. Simulation results using with SAPF}

The source current waveform and its harmonic spectrum (THD) after introducing the SAPF application using IT2FLC are respectively shown in Fig. 10 (a) and (b). The output DC capacitor voltage $\left(V_{d c}\right)$ is given in Fig. 7 (c).

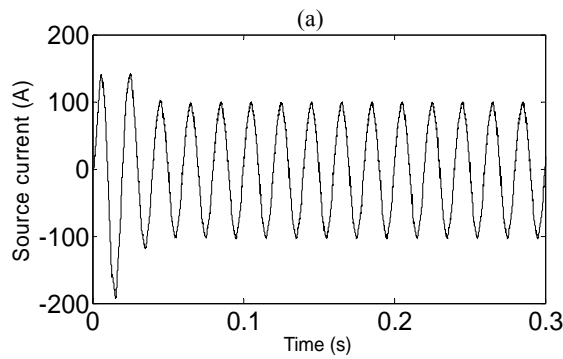

(b)

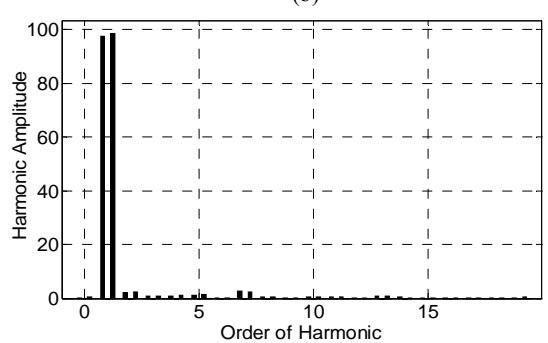

(c)

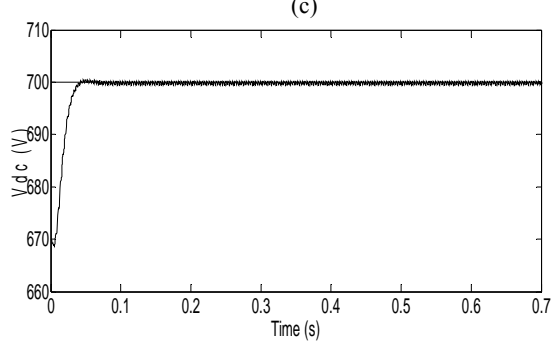

Fig. 7 SAPF control using T2FLC (a) source current (b) THD (c) $V_{d c}$

The ability of the SAPF to compensate for the harmonic current of the load is demonstrated in Fig. 7 (a) and (b). The THD dropped from $23.74 \%$ to $3 \%$ when using the SAPF.

\section{IT2FLC performance under changing system's parameters}

In order to assess the robustness of these controllers, the filter inductance $L_{f}$ has been increased by $50 \%$. Fig. 13 shows the DC bus voltage response under PI controller and IT2FLC was performed. 


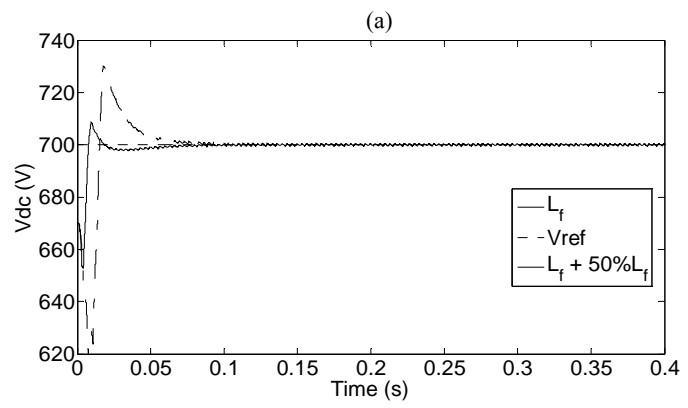

(b)

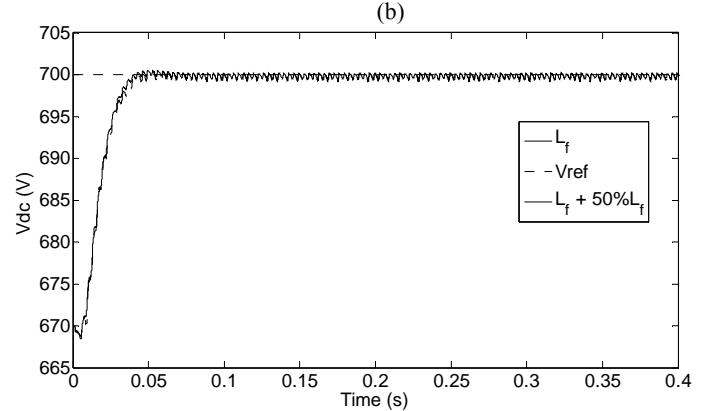

Fig. 8 Comparison of (a) PI (b) T2FLC under parameter variations.

\section{CONCLUSIONS}

The paper the control of a shunt active power filter based on type-2 fuzzy systems to mitigate harmonics and enhance the power quality under non-load conditions. The performance and robustness of the proposed controller has been evaluated in terms the harmonic distorsion of the source current waveforms and variations in the filter inductance respectively. The simulation study was performed under Matlab/Simulink and SimPowerSystems toolbox. The results show that with the proposed control scheme, the supply current waveforms were almost perfectly sinusoidal and in-phase with the supply voltage and the harmonic distortion achieved with the proposed controller (3\%) was well below the limit imposed by the IEEE519 standards.

\section{REFERENCES}

[1] N. Mendalek, K. Al-Haddad, "Modelling and nonlinear control of shunt active power filter in the synchronous reference frame," IEEE ICHQP'2000, pp. 30-35, 2000.

[2] S. K. Jain, P. Agrawal and H. O. Gupta,'Fuzzy Logic controlled shunt active power filter for power quality improvement",IEE proceedings in Electrical Power Applications, Vol 149, No.5, September 2002.

[3] H. Rudnick, Juan Dixon and Luis Moran, "Active power filters as a solution to power quality problems in distribution networks," IEEE power \& energy magazine, pp. 32-40, Sept. / Oct. 2003.

[4] D. Dirk, J. Joep, W. Rik. A new hybrid filter to dampen resonances and compensate harmonic currents in industrial power systems with power factor correction equipment. IEEE Transactions on Power Electronics, 2001, 16(6): $851-827$.

[5] N. Mendalek, K. Al Haddad, L.A-Dessaint and F. Fnaiech " Nonlinear Control technique to enhance dynamic performance of a shunt active power filter " - IEEE Proceedings Electrical Power Applications -vol.150 no 4 , july 2003.

[6] N. N. Karnik, J. M. Mendel, and Q. Liang, "Type-2 fuzzy logic systems," IEEE Trans. Fuzzy Systems, vol. 7, pp. 643-658, Dec. 1999.

[7] Jerry M. Mendel and Robert I. Bob John," Type-2 Fuzzy Sets Made Simple", IEEE transactions on fuzzy systems, vol. 10, no. 2, april 2002.

[8] D. Wu. and J. M. Mendel, "Enhanced Karnik-Mendel algorithms For interval type-2 fuzzy sets and systems," Proc. In Proc. NAFIPS, San Diego, CA, pp. 184-189, 2007.

[9] Bhuvaneswari, G.; Nair, M.G.; Kumar Reddy, S. "Comparison of Synchronous Detection and I. Cos $\phi$ Shunt Active Filtering Algorithms", Power Electronics, Drives and Energy Systems, 2006. PEDES '06. International Conference on, On page(s): 1 - 5

[10] D. Wu. and J. M. Mendel, "Enhanced Karnik-Mendel algorithms For interval type-2 fuzzy sets and systems," Proc. In Proc. NAFIPS, San Diego,CA,pp.184-189,2007. 